ISSN: 0514-7336

DOI: https://doi.org/10.14201/zephyrus201678111129

\title{
CALDAS DE MONCHIQUE (PORTUGAL): ESTADO DE LA CUESTIÓN SOBRE UN BALNEARIO ROMANO EN EL SUROESTE DE LUSITANIA
}

\section{Caldas de Monchique (Portugal): Review and up-to-date archaeological data about a Roman healing spa in the sW of Lusitania}

\author{
Silvia González Soutelo* y Fábio Capela** \\ * Grupo de Estudios de Arqueología, Antigüedad y Territorio (GEAAT). Facultad de Geografía e Historia. Campus \\ Universitario.36310Vigo.Correo-e: silviagonzalez@uvigo.es \\ ** Servicio de Arqueologia. Câmara Municipal de Monchique. Tv. da Portela, 2. 8550-470 Monchique (Portugal). \\ Correo-e:fabio.capela@cm-monchique.pt
}

Recepción: 20/10/2015; Revisión: 6/07/2016; Aceptación: 12/09/2016

\begin{abstract}
Resumen: El balneario de Caldas de Monchique es uno de los más significativos del sur de Portugal, cuyos antecedentes se remontan a época romana. Sin embargo, los estudios realizados hasta el momento han sido parcos en su descripción e interpretación, por lo que considerábamos esencial realizar un análisis más detallado que aportase nueva luz sobre este yacimiento.

En ese sentido, a partir de la visita y reconocimiento del lugar, la revisión de la documentación existente, la comparación con otros balnearios romanos y la recuperación de los materiales arqueológicos descubiertos en este enclave en los años $40 \mathrm{del} \mathrm{s}$. Xx, se plantea un estado de la cuestión sobre uno de los balnearios más destacados del so de la Lusitania.

Todo ello ha permitido conocer con mayor detalle este establecimiento y, consecuentemente, incrementar la información sobre los enclaves en los que se usaron aguas mineromedicinales en época romana, partiendo de datos más precisos y minuciosos.

Palabras clave: Aguas mineromedicinales; termas salutíferas; Algarve; arquitectura romana; sistemas hidráulicos.
\end{abstract}

АвSTRACT: In this article, we propose a review of the different aspects stated in the bibliography about the Roman healing spa of Caldas de Monchique, systematically updating the main information available on this establishment.

Our proposal is to provide an assessment of the current state of affairs of one of the most significant thermal spas in the south-west of Lusitania, taking into account new data about the Roman materials and structures identified in 40's of the $\mathrm{xx}^{\text {th }}$ century. This study will allow us not only to find out in more detail the main characteristics of this building, but also to further our data about the places where mineral-medicinal waters were exploited in the Roman Age using a more exhaustive and precise information.

Key words: Mineral-medicinal waters; healing place; Algarve; Roman architecture; hydraulic systems. 


\section{Introducción}

El balneario de Caldas de Monchique, situado a $3 \mathrm{~km}$ en línea recta de la población de Monchique (Fig. 1), es, sin duda, uno de los establecimientos termales más representativos del $s$ de Portugal ya que representa una significativa excepción en un territorio en el que no abundan los manantiales de aguas mineromedicinales de elevada temperatura $^{2}$.

Dado el interés histórico y arqueológico que presenta este enclave dentro del catálogo de establecimientos de baños con aguas minerales probablemente explotadas en época romana en territorio portugués (Acciaiuoli, 1944: II, 32-35; Frade 1993: 890), hemos realizado una revisión minuciosa de sus características arquitectónicas y materiales; esto nos ha permitido reconocer la singularidad de este enclave y evitar confusiones y erróneas lecturas que, en muchos casos, se han repetido en sucesivas referencias ante la falta de referencias a las fuentes originales.

Gracias al acceso a la documentación ${ }^{3}$ depositada fundamentalmente en la Universidad de Lisboa, en la Biblioteca Nacional de Portugal, en el Archivo del ILME, así como en los fondos del Museo

1 Sirva este trabajo como tributo al ingeniero L. Acciaiouli y a la Dra. H. Frade, por su inicial puesta al día de estos complejos en el ámbito portugués que constituyen el punto de partida fundamental para el estudio de la explotación y uso de las aguas mineromedicinales de época romana en el territorio lusitano.

2 En la sierra de Monchique se localizan, por ejemplo, otras dos fuentes minerales: Fonte Santa da Malhada Quente, con aguas bicarbonatadas sódicas, y la Fonte Santa da Fornalha o Termas da Fornalha, con bicarbonatadas cálcicas; la termalidad en ningún caso alcanza los $30^{\circ} \mathrm{C}$ y no presentan evidencias de explotación en época antigua. Para un resumen de los principales ejemplos de surgencias minerales en el distrito de Faro $c f$. http://www.aguas.ics.ul.pt/faro.html.

3 La investigación y consulta bibliográfica ha sido realizada y financiada en el marco del proyecto I + D de la Fundación Séneca (15387/PHCs/10) El tejido balneario durante
Municipal Dr. J. Formosinho de Lagos ${ }^{4}$, junto con la visita al propio enclave y la posterior localización de los restos arqueológicos hallados a mediados del s. $\mathrm{xx}$ en este lugar, hemos aunado y puesto al día la información disponible sobre este yacimiento ${ }^{5}$. Así

la época romana y tardoantigua en Hispania: documentación y estudio de la epigrafía y la numismática de los balnearios y las fuentes mineromedicinales; además se ha asociado al proyecto de I + D + i del MICINN (HAR2011-25011) La explotación y comercio de los recursos naturales en el $N$ de Hispania romana: lapis, metalla, aqua.

4 Expresamos especial agradecimiento a la Cámara Municipal de Lagos por la atención y amabilidad prestadas durante la consulta de los materiales del Museo Arqueológico Municipal, y especialmente al personal de dicho Museo y del Archivo de Lagos por su excepcional ayuda y profesionalidad.

5 Agradecemos muy sinceramente al profesor de la Universidad de Algarve (UAlg), Dr. João Pedro Bernardes, las interesantes referencias aportadas a la revisión de este trabajo; así como al Dr. Rui Parreira, de la Direção Regional de Cultura do Algarve, y a la Dra. Elena Morán, 
hemos podido revisar y valorar los indicios existentes, así como retomar los aspectos constructivos y funcionales de este enclave para encuadrarlos y establecer su comparación con otro tipo de establecimientos de época romana de la Península Ibérica ${ }^{6}$.

Caldas de Monchique es un enclave termal situado en el marco geográfico de la sierra de Monchique, dentro de la freguesía y cámara municipal homónima, en la región portuguesa del Algarve y concretamente en el distrito de Faro. Sus aguas minerales están clasificadas como bicarbonatadas, sódicas y fluoradas, con una temperatura de $31{ }^{\circ} \mathrm{C}^{7}$ -pozo de S. João de Deus- (Cruz, 1992: 23). En ese sentido, el complejo se ha surtido históricamente de tres surgencias tradicionales ${ }^{8}$ : S. João de Deus -la que se identifica como más antigua-, Santa Teresa y Pancadas, situadas a ambas márgenes del enfilado valle dibujado por el paso del arroyo As Caldas que condiciona el espacio en el que manan (Fig. 2).

En toda la sierra de Monchique existen abundantes yacimientos prehistóricos, fundamentalmente en el entorno de los manantiales -y quizás en relación con ellos-; en ese horizonte histórico se ha centrado la mayoría de las publicaciones arqueológicas sobre este espacio natural (Viana et al., 1950, 1955; Formosinho et al., 1953; Capela, 2014). Sin embargo, salvo puntuales referencias a la aparición de materiales descontextualizados en esta freguesía y sus colindantes, son escasas las menciones a yacimientos de época romana, exceptuando la referencia al posible yacimiento del Cerro do Castanho (Santos, 1972: 65-67), situado entre el núcleo

arqueóloga de la Cámara Municipal de Lagos, su ayuda e indicaciones.

6 Sobre esta temática $c f$. fundamentalmente los trabajos de González Soutelo (2012, 2013) sobre los principales complejos termales en la Península Ibérica.

Según las analíticas realizadas en el propio balneario, el manantial de S. João de Deus podría alcanzar los $32{ }^{\circ} \mathrm{C}$; agradecemos esta información a C. Sintra, Spa Manager de la Villa Termal das Caldas de Monchique, a quien agradecemos su ayuda.

8 En esta relación, no incluimos los manantiales surgidos por pozos de perforación, ya que son de creación reciente. urbano de Monchique y la población de Caldas, y ya descrito por Veiga Ferreira (1952) ${ }^{9}$.

Si bien estas aguas debieron de haber sido conocidas y utilizadas posteriormente en época árabe, no será hasta el s. XV cuando se citen específicamente sus cualidades y el aprovechamiento salutífero que de ellas se podía obtener. Así, el cronista Rui de Pina dejó constancia de la visita al lugar del rey $\mathrm{D}$. João II en 1495 en busca de una cura para sus dolencias ${ }^{10}$.

Las estructuras creadas para su explotación se han superpuesto durante siglos. Las primeras construcciones estables de las que tenemos referencia son las realizadas por el obispo de Algarve, F. Barreto, en 1649, erigidas para facilitar el uso y acceso a estos manantiales salutíferos sobre todo a los más pobres y enfermos. En 1672 el conde de Vale de Reis ordena construir una nueva casa de baños, pero no será hasta 1691, tras el traslado de la posesión y explotación de estas aguas al obispo del Algarve y sus sucesores, cuando se reformen las edificaciones anteriores, dotando de nuevas instalaciones al complejo e incorporando personal sanitario acorde con su funcionalidad esencialmente terapéutica, a lo que se unirá la creación de nuevos y mejores accesos a este enclave termal (Acciaiuoli, 1944: Iv, 169) ${ }^{11}$.

9 A este enclave se asocia la presencia de "uma poderosa muralha", un camino pavimentado - de cronología dudosa- y restos constructivos que, según Ferreira (1952: 53-54), estaban asociados a un lagar romano.

10 Curiosamente la publicidad que este rey pudo hacer de las aguas fue más negativa que positiva, ya que murió días después por causas inciertas tras una larga enfermedad en la próxima población de Alvor (Freitas, F. J. Martins: As Caldas de Monchique nos séculos XIX e XX. Contributo para um estudo monográfico. Tesis doctoral inédita defendida en 2003 en la Univ. de Lisboa, p. 33). Según las crónicas, no fue el último de los monarcas portugueses en visitar y utilizar las propiedades de estas aguas, pues se menciona que reyes posteriores como D. Sebastiāo (1573) o la reina D. Amelia de Orleáns y D. Carlos I (1897) fueron asiduos visitantes (Gascon, 1993: 195).

11 La web http://www.aguas.ics.ul.pt/index.htm está destinada a la recopilación, inventario y difusión de manantiales de aguas mineromedicinales en Portugal, a raíz de los proyectos de investigación $A$ água como agente terapêutico: etnografia comparada das termas em Portugal e no Brasil (POCTI/ANT/41192/2001) y Das termas aos 'spas': reconfiguraçôes de uma prática terapêutica (POCTI/ANT/47274/2002), 
114 S. González y F. Capela / Caldas de Monchique (Portugal): estado de la cuestión sobre un balneario romano...
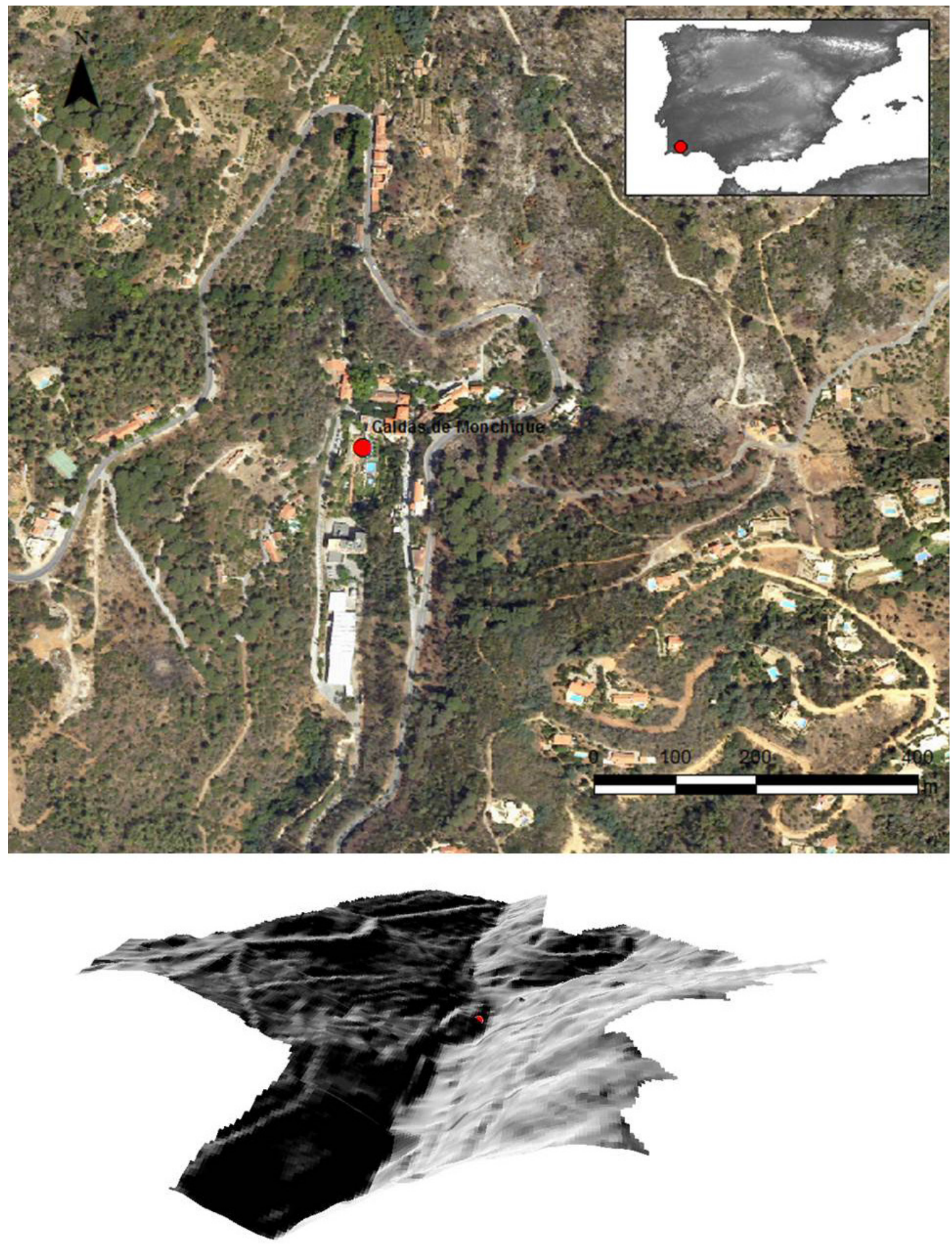

FIG. 2. Fotografía aérea y representación 3D de la topografía de Caldas de Monchique. 
A finales del s. XVIII, en 1789, se realiza la gran reforma de Caldas, con la ampliación del balneario descrita por Tavares (1810: 173) y la asignación de un médico director dedicado a la supervisión del tratamiento. Entonces se realiza también por primera vez un análisis de las aguas de los manantiales permitiendo un adecuado conocimiento y uso de sus propiedades salutíferas.

En 1834, durante el proceso de secularización de bienes eclesiásticos en Portugal, Caldas de Monchique pasará a ser administrado por el Gobierno Civil de Faro. Ya en 1872 se establece un nuevo Regulamento do estabelecemento termal de Monchique por el que la dirección y administración de las Caldas debe ser ejercida obligatoriamente por un médico-director que también asumiese la gestión y las reformas necesarias del edificio para un correcto aprovechamiento de las aguas y además elaborara un relatorio anual $^{12}$. Las críticas y sugerencias para la mejora de los baños se sucederán en los años siguientes; en 1938 el complejo pasa a depender de la Direção Geral de Minas e Serviços Geológicos, que insiste en la necesidad de revisar y mejorar las captaciones de las aguas del establecimiento. Así, tras haber sido demolidos algunos de los edificios del balneario y expropiadas algunas de las propiedades vecinas que podrían afectar negativamente a las cualidades del manantial subterráneo, dicha Direcção procedió entre 1942-1949 al estudio y adecuación de las captaciones de los manantiales de Caldas de Monchique. El director médico del balneario, J. de Sousa Costa, fue gran defensor del potencial histórico

financiados por la Fundação para a Ciência e a Tecnologia, y realizados por un equipo de investigación del Instituto de Ciências Sociais da Univ. de Lisboa y el Centro de Estudos de Antropologia Social.

12 Documento similar a las memorias que los médicos-directores de este tipo de instalaciones elaboraron en España a raíz del Real Decreto de 1816 de Fernando VII sobre las aguas minerales del reino. En él se recopilaba información sobre tratamientos, pacientes, bañistas y otros hechos destacables que se produjesen durante la estación de baños -de mayo a septiembre-. Esta información es altamente valiosa para conocer de forma detallada los hallazgos e identificar las modificaciones y reformas realizadas en el complejo durante esos años. del lugar de Caldas de Monchique y es entonces cuando se constatan y documentan los principales restos arqueológicos de este lugar.

Tras el 25 de abril de 1974 el establecimiento termal pasó a manos del Ministério do Comércio e Turismo y su explotación quedó a cargo de ENATUR, que posteriormente fue comprado por la Fundação Oriente, creándose la Sociedade das Termas de Monchique $\mathrm{SA}^{13}$.

\section{Presencia romana en Caldas de Monchique}

Sin duda, la ocupación romana de esta sierra va fuertemente unida a la presencia de los manantiales. Aunque no dudamos de que pudieron existir caminos tradicionales para comunicar la sierra con la costa, es posiblemente en época romana cuando se crea un eje viario secundario que uniría el área costera del Algarve con este enclave; de esta forma se facilitaría el paso por la sierra de Monchique y la ocupación de esta parte del territorio lusitano desde época temprana. Aunque no se han documentado testimonios epigráficos ni constructivos - puentes o miliarios- que puedan adscribirse a época romana ni se ha rastreado un trazado específico, algunos investigadores apuntan la existencia de tramos viarios en el entorno de Caldas de Monchique (Viana et al., 1948; Santos, 1972; Rodrigues, 2004).

En este sentido se ha observado la existencia de, al menos, una vía de penetración que con seguridad atravesaría la sierra de Monchique ${ }^{14}$ desde la ciudad romana de Portimão - ¿Portus Hannibalis? ${ }^{15}$ hacia el N (Fig. 1), con un paso condicionado por la presencia de estas aguas, cuya importancia podría haber propiciado y condicionado el trazado de esta vía. Por tanto, este sería un espacio de interés por

13 La actual propietaria del complejo termal de Caldas de Monchique es la Sociedade das Termas de Monchique II, LDA.

14 Sobre este tema $c f$. referencias específicas en Viana et al., 1948; Santos, 1972; Rodrigues, 2004.

15 En relación con la problemática en la identificación de este topónimo $c f$. entre otros Alarcão, 2005. 
sus funciones salutíferas y religiosas, a lo que se podría sumar su adecuación como área de descanso y/o posada en el camino. Es probable que estemos así ante una vía secundaria que permitiese conectar los enclaves costeros con este balneario y con el interior de la sierra, mientras que la vía primaria con el n y e de la península se desarrollaría bien por ámbito costero, bien por el espacio central que hoy en día se utiliza como eje principal de comunicaciones (Rodrigues, 2004).

Sobre la entidad administrativa de Caldas de Monchique en época romana carecemos prácticamente de datos. Sin embargo, no sería descartable que, al igual que en otros enclaves termales -por ejemplo, Bańos de Montemayor, vinculado a la población romana de Capara-, se tratase de un enclave balneario dependiente de una próxima civitas que, probablemente, se correspondería con la vecina población romana de Portimão. En ese sentido, cumpliría el papel de un enclave salutífero en ámbito rural en el que se aprovecharía un recurso tan valioso como las aguas mineromedicinales cuya realidad estaría condicionada por el lugar de surgencia, adaptando así el establecimiento al terreno y al manantial para poder aprovechar al máximo sus cualidades salutíferas. Igualmente, como es bien sabido, esa función no estaría separada de su connotación religiosa en el mundo antiguo (como evidenciaría, por ejemplo, la aparición de epigrafía votiva) y, por lo tanto, además de un recurso de salud monumentalizado para su correcto uso, estaríamos ante un recinto de culto vinculado a estas aguas -indicado, por ejemplo, por el teónimo aquae sacrae que, como veremos, está presente en la epigrafía del lugar- al que los agüistas acudirían para mejorar sus dolencias y sus enfermedades ${ }^{16}$.

La duda surge a la hora de considerar si alrededor de este complejo termal se pudo haber creado una

16 Sobre las implicaciones específicas del termalismo antiguo, se ha trabajado mucho en los últimos años. En ese sentido, para su tratamiento desde diversas perspectivas cf. Bonnard, 1908; Pelletier, 1985; Chevallier, 1992; Oró Fernández, 1996, o Díez de Velasco, 1998, como estudios pioneros de interés; también publicaciones derivadas de congresos y proyectos como Peréx y Bazana, 1992; Peréx, 1997; Guerin y Martin, 2007; Bassani et al., 2013; Scheid, 2015, o Matilla y González, 2016. entidad poblacional ya que, como sería lógico, existirían infraestructuras básicas destinadas al alojamiento y servicio de los asistentes y usuarios de estas aguas, dando lugar a un asentamiento de cierta entidad. Sin embargo, ante la falta de prospecciones intensivas en las inmediaciones que nos den luz en ese sentido, no sería descartable esa ocupación, habida cuenta de las constantes referencias a hallazgos de época romana en las inmediaciones de este yacimiento.

\section{Principales evidencias arqueológicas de época romana presentes en el balneario de Caldas de Monchique}

Como ya hemos indicado, la ocupación del espacio natural de la sierra de Monchique presenta múltiples testimonios de una larga perduración, siendo concretamente en las inmediaciones de Caldas donde se constata una mayor concentración de yacimientos y materiales arqueológicos de diversas cronologías, caso de las necrópolis neolíticas y de la Edad del Bronce (Viana et al., 1950, 1955; Formosinho et al., 1953; Morán y Parreira, 2009: 150-151; Capela, 2014), en posición dominante en torno a los manantiales; o por las referencias a hallazgos materiales de época romana y tardorromana-visigoda, fundamentalmente monedas, así como objetos en enterramientos vinculados en su mayoría a las necrópolis de Archeta y de Alcaria (Viana et al., 1943; Santos, 1972: 60-61).

Se podría considerar, por tanto, que todos esos testimonios dan fe de la posible utilización, dada su proximidad, de los manantiales termales de Caldas de Monchique desde época muy temprana; sin embargo, sólo tenemos bien referenciada esa explotación desde época romana, a partir de los distintos materiales y estructuras descubiertos desde principios del s. Xx en el espacio de estas surgencias.

Como hemos visto, las primeras referencias indicaban la aparición de monedas en el entorno inmediato a este recurso natural ${ }^{17}$. A ello se unía

17 Aparecen múltiples referencias en: Carvalho (1939: 13-14), sobre las monedas recogidas en Rencovo y después citadas en trabajos posteriores; Gascon (1993: 55 y 247) 
la noticia del descubrimiento de construcciones en las proximidades que, tomando la referencia del Dr. Castel-Blanco, se situarían al o del balneario, en la ladera de la montaña. Así se menciona la presencia de "vestigios de antigas construçóes, provávelmente romanas -fornos de pão e pequenas casas de habitação-. [...] Com as grandes chuvas persistentes, uma parte das encostas de forte rampa se esboroa e desloca até à ravina, arrastando consigo árvores e penedias [...], deixando então a descoberto vestigios de antigas construçôes" (Franco, 1945: 8).

Sin embargo, las evidencias específicas sobre la explotación romana de los manantiales surgen entre 1942 y 1949 cuando la Direcção Geral de Minas e Serviços Geológicos realiza obras para la nueva captación y mejora de las estructuras de abastecimiento. El ingeniero Acciaiuoli (1944: II, 3235) cita la aparición de "ruinas de um edifício, numerosas moedas, uma fíbula de prata [...], muitos fragmentos de cerâmica, pedras soltas, sem valor, e uma lápide com uma inscrição, já muito gasta, na qual se podem ler algumas letras". Ese epígrafe, al que haremos referencia posteriormente, está dedicado a las Aquae Sacrae (IRCP $56=$

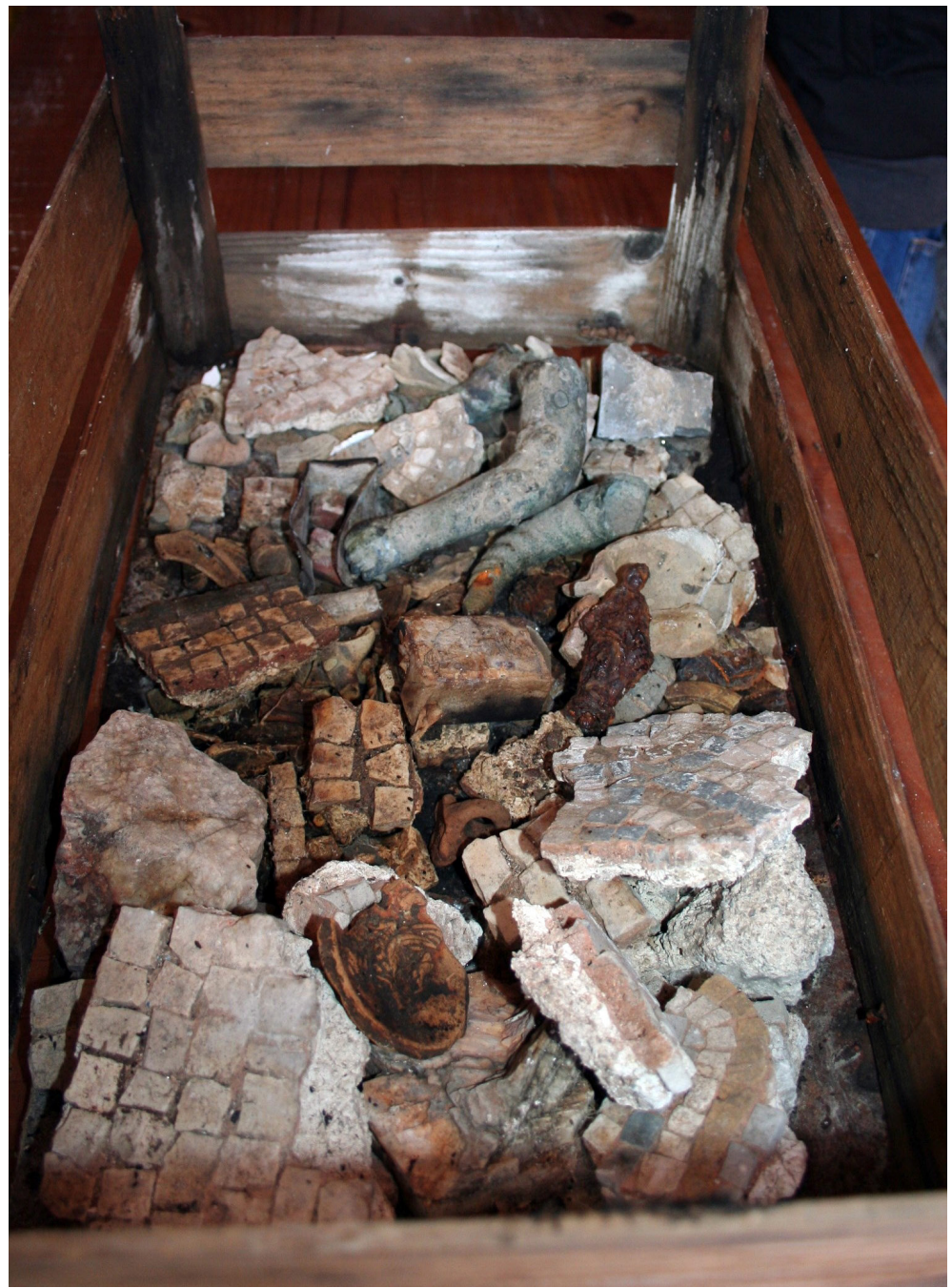

FIG. 3. Materiales arqueológicos recuperados en las ruinas del balneario provisional antiguo de Caldas de Monchique. indica: "Lembro-me, muito bem, de ter visto uma pequena moeda romana de ouro, muito perfeita e bem conservada, do imperador Honório, que foi encontrada na Foia (en nota n. ${ }^{\circ}$ 15: é a que vem desenhada na pág. 14, das Memórias das Caldas de Monchique, do Sr. Dr. Aug. Silva Carvalho)”.

Este mismo autor, en su n. 16, comenta que “... Julio Lourenço Pinto, no seu livro O Algarve (1894: 136), fala de uma moeda de bronze encontrada perto da ribeira do Banho e classificada pelo Dr. Estácio da Veiga como indicando, com toda a probabilidade de um facto histórico, a origem das termas de Monchique que se sabe terem sido usadas pelos romanos"; también Formosinho et al. (1948: 3) mencionan la aparición en 1931 y 1932 de monedas romanas en el lugar de Cortez, cerca de Caldas.
AE 1955,262 = RAP 240) y es la pieza más conocida del conjunto de materiales localizados en las inmediaciones del manantial de S. João (Franco, 1942; 1945: 11; Costa, 1957: 8; Díez de Velasco, 1998: 38, 78-79).

Durante las obras se localizaron igualmente otros materiales romanos que fueron documentados por Sousa Costa, entonces médico-director del balneario; a él se deben los dibujos publicados de las piezas y la cesión de gran parte de las fotografías a investigadores de la zona. Principalmente fueron Formosinho (1947, 1953), Viana (Viana et al., 
1948) y Ferreira quienes publicaron las noticias más completas al respecto ${ }^{18}$.

El principal conjunto de materiales arqueológicos fue localizado junto a la naciente de mayor temperatura (S. João), donde también se localizaron restos constructivos de cierta entidad, como veremos a continuación. Gran parte de los objetos (Fig. 3) mencionados por Formosinho (1948 y Formosinho et al., 1953) fueron afortunadamente localizados en el contexto de esta investigación ${ }^{19}$. Conforman los siguientes bloques:

a) Materiales constructivos: fundamentalmente se hace referencia a la presencia de ladrillos y tégulas como los materiales abundantes; sin embargo, solo tenemos una sucinta descripción, sin que se haya

18 Estos investigadores fomentaron las actuaciones arqueológicas en los alrededores de Caldas, fundamentalmente en las necrópolis de la Edad del Bronce abundantes en este territorio. José dos Santos Pimenta Formosinho fundó en 1932 el Museo Municipal de Lagos, donde está depositada la mayoría de los objetos de esas necrópolis, aunque sorprendentemente no se documenta ningún hallazgo romano en sus publicaciones. En ese sentido, queremos agradecer al personal del Museo y Archivo Municipal de Lagos su excelente disposición y amabilidad para consultar sus fondos. Solo en casos puntuales se identifica la referencia a la conservación de materiales en las oficinas del establecimiento termal, como sucede en el caso de las aras expuestas en una sala detrás de la recepción del Villa Termal das Caldas de Monchique. El resto de los materiales publicados estaban en paradero desconocido hasta este momento. Gracias a las indicaciones de la investigadora Ana Pinto y a las referencias del Dr. Rui Parreira, pudimos localizar la mayoría de los materiales publicados (caso de la estatuilla, los objetos de bronce y gran parte de la cerámica y los fragmentos de mosaicos publicados) entre los restos del balneario provisional antiguo de Caldas de Monchique.

19 Entre el conjunto de materiales redescubiertos no se encontraban todos los objetos citados en la bibliografía, pero sí una significativa mayoría. Desgraciadamente falta el conjunto de monedas citado, los alfileres de bronce y un pequeño objeto de oro ( $c f$. listado que presentamos). Queremos agradecer las facilidades proporcionadas por los propietarios de este establecimiento para el estudio del complejo termal romano, la colaboración y amabilidad del personal del centro, así como la ayuda prestada para localizar y hacer una primera revisión de los objetos que en nuestra visita en febrero de 2015 pudimos recuperar. conservado ningún ejemplar ${ }^{20}$. Junto a estos objetos, se menciona la presencia de canalizaciones realizadas con ímbrices y ladrillos (Formosinho, 1948: 214), así como fragmentos de una tubería de plomo (Ferreira 1963: 14, fig. 1, n. ${ }^{\circ}$ 5) ${ }^{21}$, junto a restos de $\operatorname{mosaicos}^{22}$ de los que solo se conservan pequeños fragmentos polícromos y abundantes teselas sueltas (Fig. 4).

b) Cerámica: la mayoría de los materiales cerámicos descubiertos a mediados del s. xx fueron publicados incluyendo fotografías y dibujos de las piezas más representativas (Formosinho et al. 1953). Sin embargo, la falta de una descripción detallada, así como la ausencia de un contexto arqueológico específico, dificultaba la interpretación de estas piezas

20 Se menciona la presencia de “... vários tijolos lisos, grandes, rectangulares, e outros de diversos feitios e tamanhos; cinco fragmentos de imbrices, sendo um muito grosso, con cerca de 0,04 m de espessura; treze tijolos pentagonais para algumas tégulas..." (Formosinho, 1947: 211). Concretamente en Formosinho et al. (1953: 152-153) se describe cada uno de los materiales, mencionando 3 ladrillos bessales $(23 \times 22 \times 4 \mathrm{~cm})$; algún ladrillo ¡cuneatis?; ladrillos de 42 x 16 × $6 \mathrm{~cm}$; ladrillos pentagonales, como base de una de las pilas descubiertas en 1946; junto con tégulas e ímbrices, materiales todos ellos localizados junto a la naciente de mayor temperatura (S. João).

21 Fragmentos de una fistula plombei descritos como "formado por folha desse metal enrolada em cilindro e cujos bordos longitudinais se encontravam ligados apenas por simples compressão (martelamento)"; según Carvalho (1964) se trataría de un metal de gran pureza, posiblemente un mineral foráneo.

22 Formosinho (1948: 211) señala que aparecieron "muitos fragmentos de mosaicos policromos que formavam pavimentos, predominando os do tipo de cordão a quatro e cinco cores". Algunos de ellos formaban parte del relleno de uno de los estanques: "foram estes restos de pavimentos lançados como simples material de enchimento em um dos tanques agora descobertos durante os desaterros. Notam-se dois tipos de opus vemiculatum: o de pedrinhas maiores, de que nestes restos só apareceram brancas; o de tesselas mais miúdas, do qual aqui apareceram bocados com desenho polícromo (amarelo, cinzento-escuro ou ardósia, e vermelho ou cor do tijolo, em fundo branco)" (Formosinho et al., 1953: 153). También se conservaban en el balneario abundantes teselas y fragmentos de mosaico de reducidas dimensiones. 


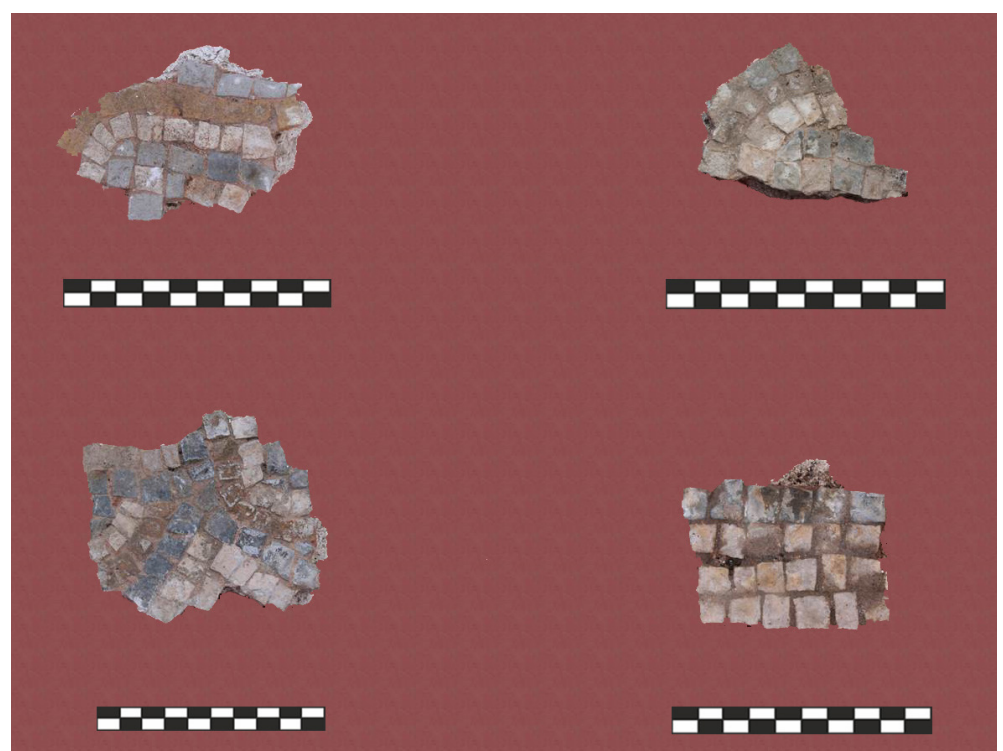

FIG. 4. Fragmentos de mosaicos recuperados y publicados previamente por Formosinho et al. (1953: est. XXXIII).

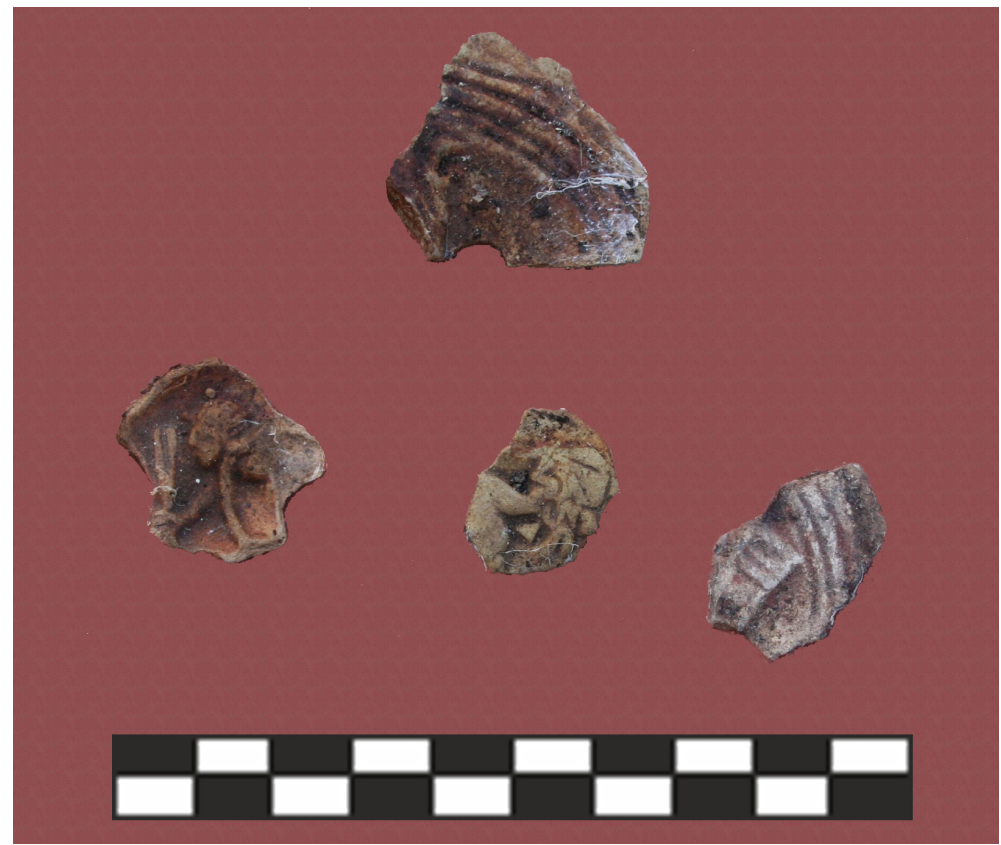

FIG. 5. Fragmentos de las lucernas figuradas recuperadas y publicadas por Formosinho et al. (1953: 145, fig. 61, 63-64 est. XXIX-XXX).

y la posibilidad de su identificación cronológica, aspecto que será revisado tras el redescubrimiento de estos materiales. En términos generales, podríamos hablar así de una selección de piezas, entre las que destacan un pico de mortero, fragmentos de sigillata posiblemente itálica mal conservados y fragmentos de lucernas -al menos 18 individuos- con decoraciones figu$\operatorname{radas}^{23}$, que permiten encuadrar todo el conjunto en el s. I d. C., siendo las piezas más antiguas de principios-mediados de ese siglo. Dichos materiales están en proceso de estudio para concretar más su tipología y cronología (Fig. 5).

c) Objetos metálicos: sin duda, los elementos más singulares entre los localizados en los años 40 (Formosinho et al., 1953) y recientemente recuperarados son varias piezas de bronce (Fig. 6). Hay un fragmento hueco del brazo izquierdo de una figura humana en buen estado de conservación ${ }^{24}$, posiblemente realizado con la técnica de fundición a la cera perdida. El codo se presenta ligeramente doblado y la mano, realizada con gran detalle, en posición semicerrada, quizás preparada

23 Los materiales hasta ahora recuperados apuntan a un arco cronológico muy concentrado en el s. I d. C. En el caso concreto de las lucernas, se aprecia un conjunto blanquecino que se adscribe al arco productivo sudbético y ejemplares de pastas y engobes rojizos claramente itálicos. Entre las decoraciones identificadas destaca una representación zoomorfa de dos aves enfrentadas; así como la posible escena de uno de los trabajos de Hércules en el jardín de las Hespérides; una representación de un posible symplegma erótico; temas zoomorfos como la representación de las pinzas delanteras de un cangrejo; así como un tipo con venera central (tipo Sotomayor D1/Dr. 3) y de volutas (del grupo Dr. 9). Indicaciones, a partir de la documentación gráfica, fundamentalmente referidas por la Dra. Macarena Bustamante, a quien agradecemos sus puntualizaciones y comentarios. Materiales en proceso de estudio.

24 Similar al ejemplar conservado en el MAN, n. ${ }^{\circ}$ inv: 18462, procedente del Santuario del Pedro de Son Corró (Mallorca). 

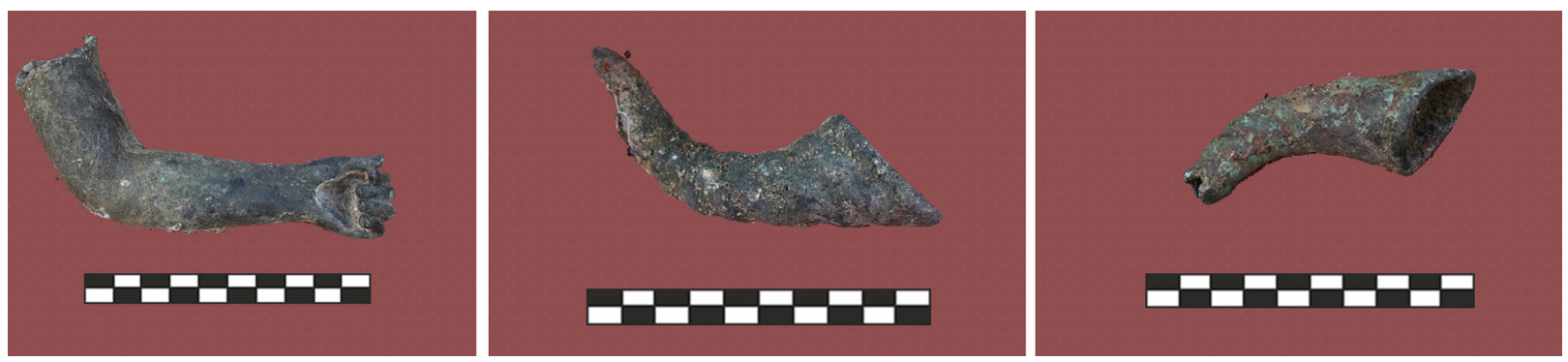

FIG. 6. Objetos de bronce publicados por Formosinho et al. (1953: est. XXXI y XXXII).

para sustentar algún elemento. Esta pieza aparece acompañada por dos cornucopias (de $10 / 11 \mathrm{~cm}$ de largo y $3 \mathrm{~cm}$ de diámetro máximo), igualmente huecas, que deberían estar asociadas a alguna otra estatuilla no conservada ${ }^{25}$. En el conjunto descrito también se incluye una dudosa escultura femenina, de pequeñas dimensiones $(8 \mathrm{~cm}$ de alto), considerada inicialmente de bronce (Formosinho, 1948: 11), que fue identificada con la representación de una divinidad u oferente; dicha pieza aparece provista de un elemento de engarce en su base para ir colocada en una peana ${ }^{26}$.

Dentro de ese conjunto, se mencionaban también otros objetos, como la ya citada fistula plumbei, una palmeta de oro en forma de hoja ${ }^{27}$ (Formosinho

25 Tal y como sucedía en el caso de los materiales anteriores, estos objetos serán tratados para su restauración y estudio, por lo que aquí solo presentamos una brevísima descripción.

26 Sobre esta pieza, tras su localización, surge la duda sobre su interpretación y antigüedad, ya que el material en el que está realizada presenta una alteración singular, al tiempo que no hemos documentado paralelos significativos para su caracterización. Así, si bien se asocia con el conjunto de materiales romanos aquí localizado, no se especifica exactamente en qué punto del enclave termal ni cuándo se encontró, ya que, por ejemplo, Formosinho (1948: 9) solo menciona que fue un hallazgo posterior al resto de las piezas. Hasta que pueda ser tratada y analizada en detalle, dejamos aquí abierta su interpretación.

27 Piezas similares, aunque fundamentalmente en plata, se han localizado en otros balnearios de época romana como el de Vicarello (Gasperini, C.: Il tesoro di Vicarello: Nuove considerazioni. Lavoro di ricerca. Trabajo de investigación inédito presentado en 2007 en la Univ. Autónoma de Barcelona, pp. 40-45 y 70) o en Vichy (Corrocher, 1981: lám. 24, fig. 2). et al., 1953: 148), hoy en paradero desconocido; monedas de amplia cronología, desde los ss. I-IV d. C. (Viana et al. 1948: 6; Formosinho et al., 1953: 150 y est. xxxII; Abad, 1992: 172-17328), no localizadas; dos objetos de hierro, un fragmento de tijera -conservado- y un ¿molde de parrilla circular con divisiones triangulares?; así como 115 alfileres de plata, con cabeza retornada, actualmente perdidos (Formosinho et al., 1953: 150) ${ }^{29}$.

d) Materiales epigráficos: son los elementos que mejor confirman la idea del valor sacro de los manantiales mineromedicinales que dieron lugar a este balneario. Son dos inscripciones de carácter votivo (Fig. 7) que hoy están expuestas en una de las salas de recepción. Se trata de un ara votiva de tamaño medio y un árula, ambas realizadas en piedra caliza; la primera es el conocido altar votivo dedicado a las Aquae Sacrae $(\operatorname{IRCP} 56=\text { AE 1955, } 262=\operatorname{RAP} 240)^{30}$,

28 Abad (1992) realiza un estudio de las monedas publicadas como procedentes de Caldas de Monchique y actualmente en paradero desconocido; ese conjunto presenta una amplia cronología con algunos ejemplares tempranos de ¿Augusto?, Tiberio y Claudio, pero aquellas que pudieron haber sido localizadas en los manantiales son en su mayoría del s. IV-principios del s. v d. C. (Formosinho et al., 1953: 153). Esta amplitud cronológica no coincide con los materiales cerámicos conservados que son fundamentalmente del s. I d. C.

29 Incluimos aquí la mención a dos botones de plata con escenas de cazas, de cronología incierta, posiblemente modernos (Lyster, 1945: 10-12; Formosinho et al., 1953: 154-156); desconocemos su ubicación actual aunque, con dudas, fueron incluidos en este conjunto.

30 Lectura e interpretación de la dedicación a las Aquae revisada en Díez de Velasco (1998: 31 y 78-79) y Andreu (2010: 193-196). 

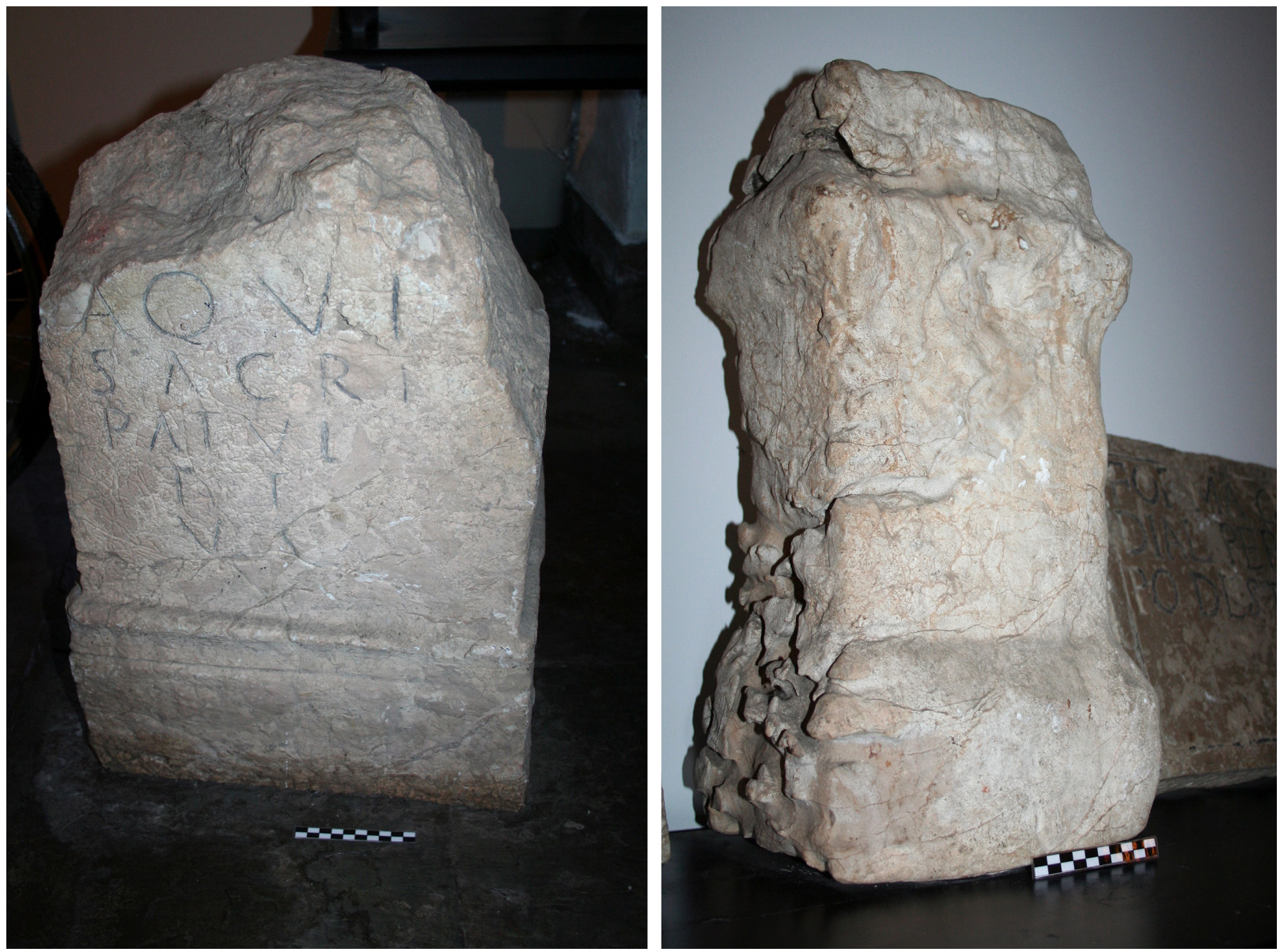

FIG. 7. Aras votivas depositadas en el balneario de Caldas de Monchique.

cuyo dedicante ofrece dudas y cuya procedencia parece ser local; los caracteres apuntan una datación temprana, en torno al s. I d. C. (Formosinho et al., 1953: 145; Encarnação, 1984: 102, n.o 56; Andreu, 2010: 195). La segunda pieza hoy carece de inscripción, aunque parece probable que el texto se haya podido perder por su exposición al agua.

\section{El balneario romano de Caldas de Monchique}

Centrándonos ya en la construcción del edificio romano para el aprovechamiento de las aguas mineromedicinales, según los restos constructivos identificados, el edificio se situaría a lo largo del valle de la Ribeira do Banho, en las inmediaciones o sobre la fuente más importante del conjunto, la de
S. João, donde debió situarse la captación principal del complejo a juzgar por el caudal de este manantial, su temperatura y por el hallazgo de la mayoría de los objetos romanos descritos (Acciaiuoli, 1944: II, 35; Formosinho, 1948: 209).

Desafortunadamente, tal y como relatan Franco (1945: 7) y Acciaiouli (1947: 111-126) y como puede comprobarse a partir de fotografías, durante las obras de preparación de las nuevas captaciones para el balneario moderno, efectuadas entre 1942 y 1949, se arrasó totalmente el espacio donde se localizaron las estructuras romanas (Fig. 8); se trataba de alcanzar la roca madre y, de esa forma, adecuar la captación para su sellado, fundamentalmente en el caso de los manantiales de S. João y Sta. Teresa.

Aunque no hay datos para conocer la configuración del sistema de captación romano, tal vez uno 


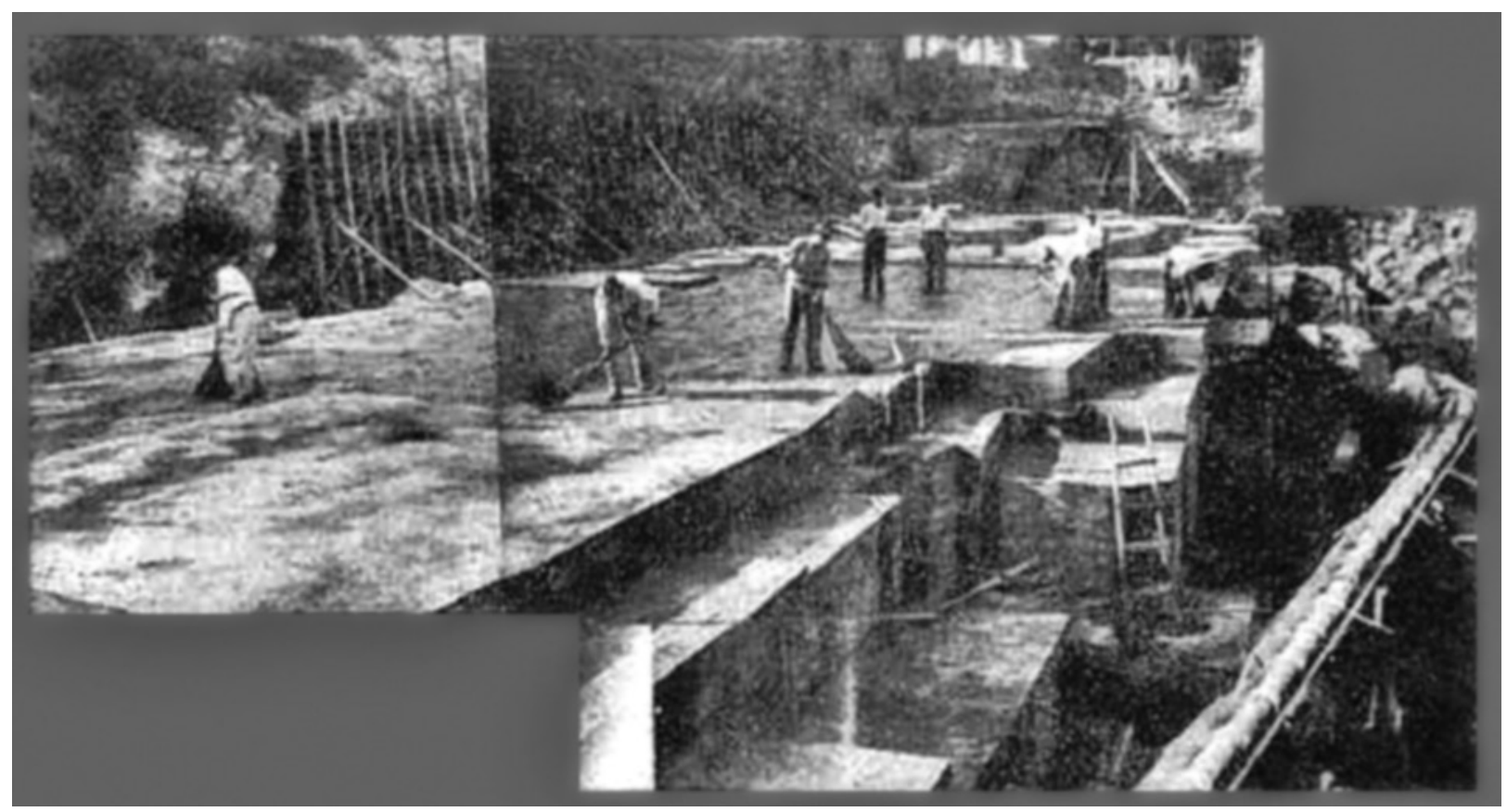

FIG. 8. Imagen de los trabajos realizados en el entorno de los manantiales para adecuar la captación de las aguas y construir el edificio provisional del balneario (Acciaiouli, 1943-46: 120).

de los aspectos más significativos a la hora de comprender la organización de ese establecimiento termal, la presencia de otro tipo de estructuras en las inmediaciones del manantial podría permitir la identificación del sistema de organización de este espacio.

En un primer momento se menciona la aparición de varios estanques realizados con muros de opus incertum y cubierta en bóveda aparejada en algunos puntos (Fig. 9), como se aprecia en las fotografías publicadas por Acciaiuoli (1944: II, 33; Franco 1945: 7; Formosinho et al., 1953: est. XXVIII) y con pavimentos diversos, tanto de ladrillo, como de opus signinum o mosaico ${ }^{31}$ (Ferreira, 1963: 16, n. a).

En 1963 Ferreira publica una hipotética planta del balneario antiguo de Caldas de Monchique donde, a partir de las construcciones que él

31 Aunque la mayoría de los autores describen el mosaico localizado en Caldas de Monchique como opus vermiculatum, los fragmentos recuperados muestran que estamos ante un opus tessellatum que, con teselas de dimensiones clásicas $(1 \times 1 \mathrm{~cm})$, representa motivos geométricos-cordones, fundamentalmente- polícromos.

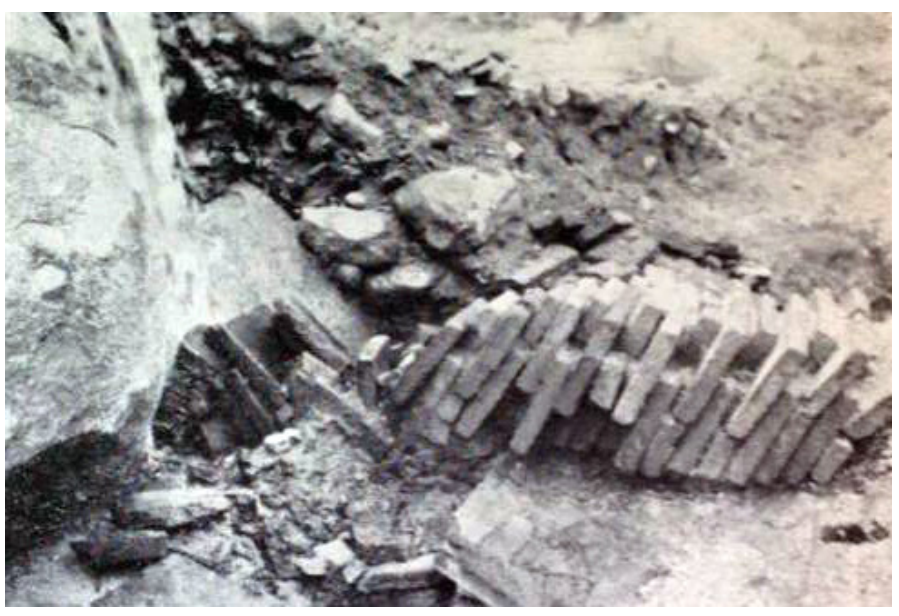

Fig. 9. Restos de bóveda aparejada de ladrillo descubierta durante las obras (según Formosinho et al., 1953: est. XVIII).

mismo pudo reconocer, pero, sobre todo, con los datos y fotografías que entonces le mostraron, realiza una descripción gráfica del posible edificio (Fig. 10). Según este autor (Ferreira, 1963: 16), toda la edificación abarcaría un área aproximada de $18 \mathrm{~m}$ de anchura y cerca de $50 \mathrm{~m}$ de longitud, sin alcanzar el ámbito más al s de esta área del valle, donde se encuentran las fuentes de la Pancada. 


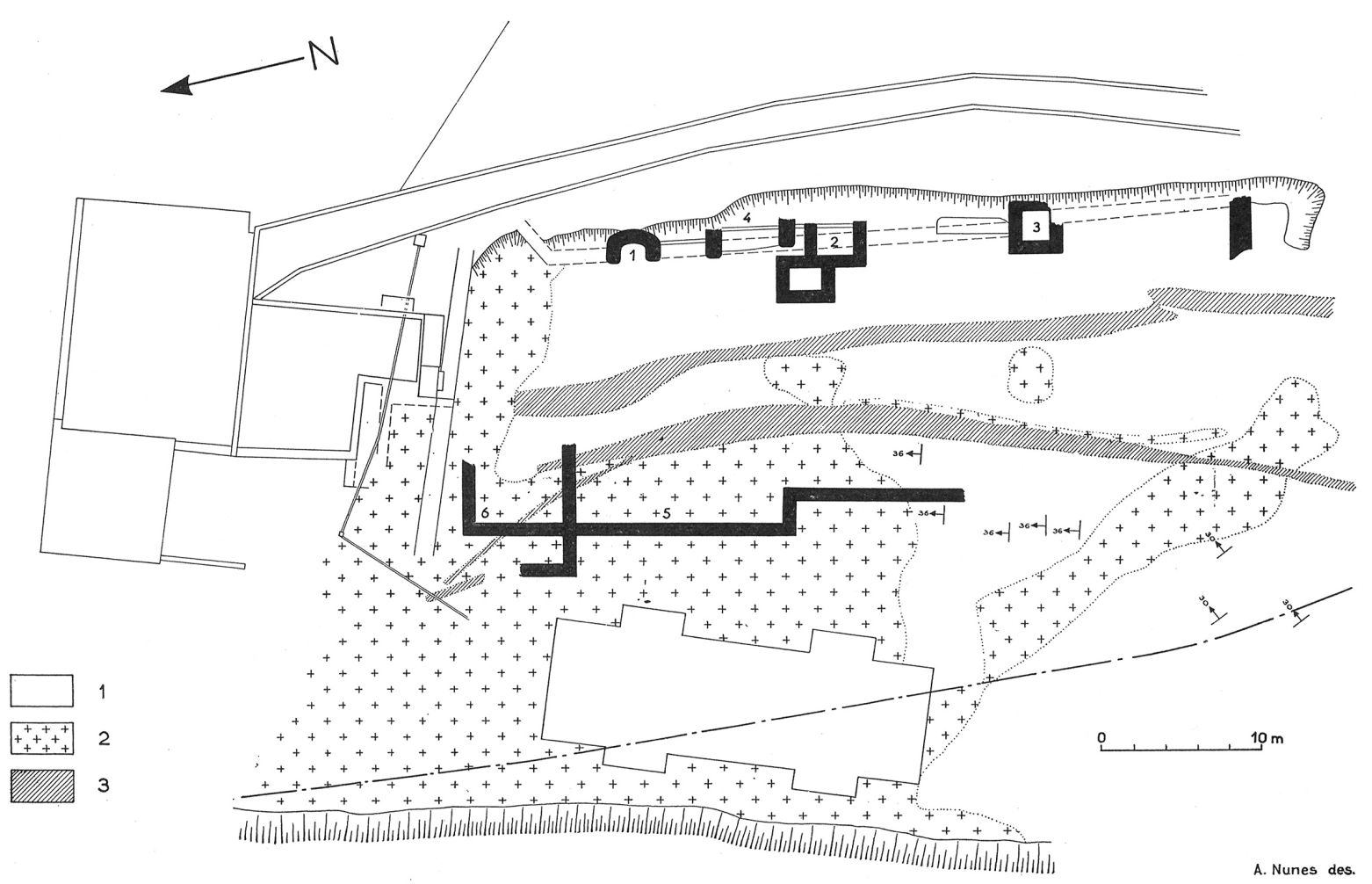

Fig. 10. Plano con la localización de los principales restos constructivos del balneario romano de Caldas de Monchique (Ferreira, 1963).

La descripción del conjunto de salas (Fig. 11) presenta las siguientes características (Ferreira, 1963: 16):

a) En el lado E del valle se menciona la aparición en 1947 de una construcción circular (Fig. 8, n. $\left.{ }^{\circ} 1\right)^{32}$ con pavimento de opus signinum, restos de ladrillo y muros de mampostería, que fue considerada como posible depósito abovedado. En el relleno de esa sala se recogieron teselas, una argolla de bronce y monedas. Según el plano de Ferreira (1963: 15), esa estancia-depósito tendría unas medidas reducidas, constatándose un ancho interior aproximado de $1,5 \mathrm{~m}$, con un muro de cierre de algo menos de $1 \mathrm{~m}$ de grosor.

De la estructura anterior partía una canalización que conducía a una sala rectangular pavimentada de opus signinum (Fig. 8, n.o 4). La canalización estaba realizada con material cerámico de construcción

32 Esta numeración es la recogida en el plano de Ferreira (1963).

(C) Universidad de Salamanca -ladrillos, ímbrices y tégulas- con "paredes estucadas y cantos redondeados" - posible cordón hidráulico-, que continuaba hasta la siguiente estructura (Fig. 8, n.o 2), de similares características que la anterior. A una cota más baja, se localizaba un tanque revestido de opus signinum con las juntas posiblemente provistas de nuevo con cordón hidráulico.

Algo más al s la canalización se interrumpe y se identifica un nuevo tanque (Fig. 8, n. ${ }^{\circ}$ 3) de aproximadamente 2 × 2 m y que repite las características del n. ${ }^{\circ}$ 2. Por último, se documenta el testigo de un muro de albañilería romana de mayor grosor $-1,2$ $\mathrm{m}$ aproximadamente-, perpendicular a la línea de construcciones anteriores y que, según este autor, podría estar marcando el límite del balneario de este lado suroriental del valle.

b) Ya en la vertiente o de la Ribeira, aparecen otros muros del posible complejo romano que marcarían una anchura máxima de la construcción en torno a $18 \mathrm{~m}$. Para el caso concreto de la sala n. ${ }^{\circ} 6$, 


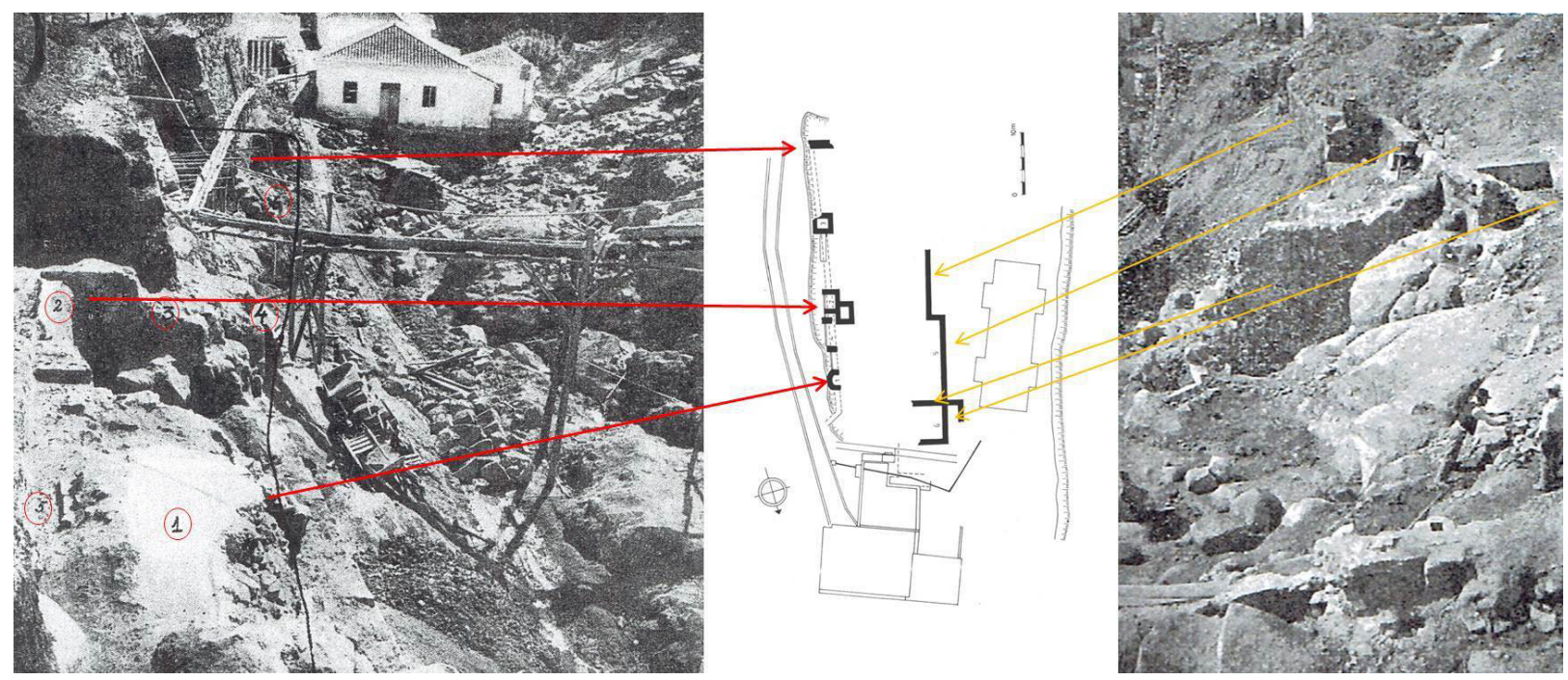

FIG. 11. Restos descubiertos en el lugar del balneario en 1947 (según Ferreira, 1963: fig. 1 y Formosinho et al., 1953: est. XXVII) relacionados con el plano de Ferreira (1963). A la imagen de la izq. la acompañan los descriptores: "1. Pavimento de opus signinum; 2. Otro pavimento bajo suspensura abovedada; 3. Paredes con opus pseudosidomum; 4. Restos de un tanque; 5. Local onde passava a canalização e onde se encontrou o cano de chumbo (fistula); 6. Última parede de fábrica romana do lado esquerdo do vale da Ribeira do Banho" (Ferreira, 1963: fig. 1).

al encontrarse junto al manantial principal de $S$. João, es posible plantear que podría haber acogido la captación primitiva -coincidente en la actualidad con la zona actual de la bouvette-.

La altura de los muros visualizados durante las obras, caso del muro medianero entre las estancias n. ${ }^{\text {os }} 5$ y 6 , alcanzaría según las fotografías una altura superior a $3 \mathrm{~m}$, aunque es necesario tomar con cautela ese dato, ya que no han podido ser confirmadas como estructuras murarias de época romana ${ }^{33}$.

Como se aprecia en la actualidad, el balneario está situado en una posición estratégica y, al mismo tiempo, compleja puesto que ocupa el punto central de una vaguada bien encajada -conocida como Val do Banho o Val das Caldas; $c f$. Fig. 2por la que discurriría un riachuelo que desde 1945 está encauzado de forma artificial ${ }^{34}$ para permitir

33 Ferreira (1963: 16) insiste en que "na parte oposta apenas conseguimos cartografar as paredes representadas na planta com os no 5 e 6 por informaçôes, nunca as vimos!!!”. La falta de calidad de las fotografías disponibles no nos permite poder aportar nuevos datos en ese sentido.

34 Según referencia de Acciaiuoli (1947: 123-124), hasta ese momento el río corría a lo largo del antiguo balneario que fue destruido entonces. aprovechar este espacio como área de piscinas al aire libre.

Este estrecho y encajado valle aparece demarcado por la roca madre, configurando el marcado cauce del antiguo riachuelo. Sobre estos afloramientos se habrían construido en diferentes épocas las pertinentes edificaciones para el aprovechamiento de las aguas. Las fuentes de S. João y Sta. Teresa, ubicadas al $\mathrm{N}$ y en el ámbito occidental del valle respecto a las otras construcciones del balneario, gracias a su recorrido descendente que facilitaría la distribución del agua, abastecerían adecuadamente las otras instalaciones del complejo.

$\mathrm{Si}$ aceptamos que las estructuras descritas formaron parte de la construcción romana, la mayor dificultad interpretativa se centra en saber cómo habría salvado el edificio romano la presencia del riachuelo. Teniendo en cuenta la altura de los muros a partir de las descripciones y de las fotografías, se observa que los tramos conservados se adaptan a la roca madre y presentan una altura significativa que les permitiría cruzar el valle (Fig. 11).

De acuerdo con esas indicaciones se podrían plantear dos posibilidades sobre la interpretación de 
las construcciones de época romana: una, dada la configuración del espacio, las estructuras podrían haberse construido de forma independiente en uno y otro lado del valle, comunicadas quizás por un pequeño puente o paso, que permitiese que el agua se distribuyera desde el punto de captación mediante diversas conducciones -tuberías de plomo o fístulae plumbei- como la documentada (Carvalho, 1964) y registrada en las fotografías; o bien, podría plantearse la hipótesis de una construcción continuada que, gracias a la canalización del arroyo, permitiese aprovechar este estrecho valle y facilitar la comunicación entre uno y otro lado del espacio rocoso que lo delimita. En ese sentido, se aprecia en las fotografías conservadas cómo las edificaciones existentes antes de las reformas de los años 40 ocupaban y aprovechaban esa sedimentación del fondo del valle para su construcción, manteniendo el riachuelo en uno de sus laterales.

Como ya hemos indicado, en los complejos termales de aguas mineromedicinales lo habitual es la captación y uso de sus aguas en el mismo punto de captación o en un espacio más próximo posible a la surgencia para aprovechar al máximo sus cualidades físico-químicas. Por tanto, la construcción de los balnearios, frente a aquellos establecimientos termales que usan agua común -con características funcionales y arquitectónicas diferentes-, presenta una doble dificultad: por una parte, la correcta captación de las aguas in situ y su posterior distribución a las instalaciones anexas creadas para su aprovechamiento; por otra, la consecuente adecuación de la estructura del edificio a la topografía del terreno, algo no siempre de fácil consecución.

Ese fenómeno es más acusado ante la frecuente asociación, por fenómenos topográficos derivados de fallas y de depresiones, de los manantiales minerales con ríos o riachuelos. Esa combinación puede provocar que muchos de esos manantiales surjan incluso en los propios cauces de las corrientes de agua, con la dificultad técnica que su captación conlleva. Las soluciones, como hemos visto, pasarían por encauzar la corriente de aquellos arroyos o riachuelos de menor caudal, o bien adecuar la surgencia para su captación y posterior traslado hasta espacios

(C) Universidad de Salamanca próximos en los que se pudiesen aprovechar, sin grandes alteraciones, las cualidades de las aguas.

Del primer caso tenemos ejemplos en el ámbito galo, donde ya en época romana se altera el recorrido de determinadas corrientes de agua para permitir una correcta captación de las aguas mineromedicinales y evitar su filtración y contaminación con otro tipo de recursos hídricos. Así se aprecia en el caso de enclaves termales como Saint-Honoré-les-Bains (Bonnard, 1908: 448-455) 35 $^{35}$ Luxeuil-les-Bains (vv. AA., 1991) o Plombières-les-Bains (Mollière, 1893: 12-16) ${ }^{36}$, donde se testimonia el esfuerzo técnico realizado en época romana para controlar el trazado de los ríos, construyendo canales o conductos que desviasen esas corrientes y permitiesen el aprovechamiento de los manantiales minerales adecuando el espacio para la construcción de piscinas y salas según las necesidades de los pacientes.

De la segunda opción también hay ejemplos documentados en Hispania y la Galia como Bourbonne-les-Bains (Bonnard, 1908: 457-462), Coren-lesEaux (Audin, 1985: 127-128) o Baños de Retortillo (Fita, 1913: 543-545), donde se hace referencia a la aparición de infraestructuras creadas en el cauce del río que permitirían, de acuerdo con un complejo sistema de captación y distribución, adecuar la surgencia del manantial para el posterior traslado y uso de las aguas minerales en puntos más elevados o mejor acondicionados que evitasen la mezcla o pérdida de las cualidades de los manantiales.

Para el caso de Caldas de Monchique desconocemos cuál fue con seguridad la solución constructiva. $\mathrm{Al}$ tratarse de un espacio fuertemente alterado por las múltiples construcciones que, como hemos visto, se fueron sucediendo en este entorno, y por otras posibles alteraciones de carácter natural -el terremoto de 1755 afectó con fuerza el s de Portugal-, el consecuente proceso sedimentario enmascaró en gran medida la configuración original de este espacio.

35 Sobre este tema también Grange, B.: Eaux guérisseuses et sources sacrées dans l'Aquitaine romaine, du Ier siècle av. J.-C. au vie siècle ap. J.-C. : un exemple de thermalisme gallo-romain. Tesis doctoral inédita defendida en 1997 en la Univ. de Bordeaux 3.

36 Grange, op. cit. n. 35. 
Posteriormente, las nuevas obras de captación de los manantiales durante los años 40 del s. xx rebajaron el sedimento en busca de la roca madre para acondicionar adecuadamente los manantiales existentes en este lugar. Esto provocó la transformación de este lugar, eliminando los depósitos y con ellos también la estratigrafía y los restos de construcción romana dejando la roca totalmente al desnudo, salvo los muros de contrafuerte y sujeción del terreno circundante, como se aprecia hoy en el fondo de este marcado valle.

\section{A modo de conclusión}

La sierra de Monchique, próxima a los enclaves romanos costeros suroccidentales de la Península Ibérica de los que posiblemente dependería y con los que mantendría buena comunicación, ofrece un rico testimonio arquitectónico y material de la ocupación diacrónica de este territorio en torno al valioso recurso de las aguas mineromedicinales.

La documentación recopilada, tanto en archivo como in situ, así como el hallazgo de un importante bloque de materiales arqueológicos, antes en paradero desconocido, ha permitido obtener una visión general de este complejo termal romano.

Su construcción testimonia la maestría en la ejecución de este edificio en un punto del terreno donde la topografía ofrece dificultades; a pesar de que los elementos documentados no permiten reconocer su estructura en detalle, evidencian una singular adaptación al terreno. A partir de una adecuada actuación edilicia se salvaría el espacio del encajonado valle para aprovechar al máximo este entorno $^{37}$, repartiendo el caudal de los manantiales termales -como así testimonian la tubería localizada in situ o la referencia a "aqueductos antigos" (Acciaiuoli 1944: I, 59)- desde el punto de captación -infraestructura romana desaparecida, que probablemente estaría en el punto más alto del

37 Ferreira (1963: 16) sugiere que se realizaría en forma de un edificio de planta rectangular (Fig. 10), hipótesis que no resulta descabellada, aunque no contamos con suficientes evidencias para confirmarlo. complejo, donde ahora se capta el manantial de $S$. João- a las distintas estancias del recinto termal. La presencia de piscinas o depósitos de reducidas dimensiones en el lado oriental del edificio podría indicar espacios de almacenamiento y distribución de agua, o bien su utilización, como sucede en muchos de estos establecimientos, para tratamientos individualizados dentro de un hipotético recinto de planta rectangular que aprovecharía en anchura el espacio existente.

En las publicaciones e informes las estructuras se describen como recintos delimitados por muros de sillería o mampostería pétrea con materiales de relleno (Franco, 1945: 7). La construcción se completaría en algunos puntos con bóveda de ladrillo, de la que se conservan derrumbes (Fig. 9) que testimonian una cubierta con bóveda aparejada similar a ejemplos como el balneario de Chaves (Carneiro, 2013) $)^{38}$, de Civitavecchia (Köehler, 2007) o de Bath (Cunliffe, 2000) y pavimentos diversos, algunos realizados en opus latericium (Formosinho, 1948: 214) y otros revestidos de mosaico. En los estanques o piscinas se observa, como es frecuente en este tipo de instalaciones, su recubrimiento con opus signinum y una posible preparación de cordón hidráulico en sus juntas que, junto con las tuberías y canales mencionados en la bibliografía, refuerzan la vinculación con el uso de las aguas en estas estructuras.

A la hora de establecer una cronología de fundación para este establecimiento carecemos de datos procedentes de intervenciones arqueológicas que aportar información estratigráfica. La cronología del conjunto de materiales recuperados, tanto de la cerámica como de los epígrafes se concentra en el s. I d. C. Esa datación es similar a la de otros establecimientos peninsulares que, en conjunto, corresponden a un momento inicial del s. I d. C.; salvo

38 También Carneiro, S. Fiadeiro (2016): "New data from the roman healing spa of Aquae Flaviae (Chaves, Portugal)”. En Matilla, G. y González Soutelo, S. (eds.): Termalismo antiguo en Hispania. Hacia un nuevo análisis del tejido balneario en época romana y tardorromana en la Península Ibérica (Proyecto "Balnearios I"). Anejos de Archivo Español de Arqueología. Madrid: csic, en prensa. 
algunos ejemplos levantinos -en Caldes de Malavella o Fortuna la etapa inicial podría remontarse al s. I a. C.-, en el resto del territorio peninsular, y más concretamente en ámbito atlántico ${ }^{39}$, la mayoría de estos establecimientos de aguas mineromedicinales parecen iniciarse en una primera fase augústea o julio-claudia ${ }^{40}$.

Evidentemente faltan por documentar diveros aspectos de cara a conocer la naturaleza del establecimiento salutífero y termal romano de Caldas de Monchique y, dada la destrucción total de las infraestructuras previas por la reutilización constante del manantial principal, resulta difícil realizar comprobaciones. Precisamente por ello, frente a la desaparición de esas evidencias, cobra interés la recuperación de algunos materiales y la revisión de los significativos testimonios ofrecidos por ingenieros y eruditos locales. Todos estos datos parecen corroborar que se trata de uno de los establecimientos balnearios más significativos en el occidental peninsular.

\section{Bibliografía}

Abad, M. E. (1992): "La moneda como ofrenda en los manantiales", Espacio, tiempo y forma. Serie II, Historia antigua, 5, pp. 133-194.

Acciaivoli, L. Menezes Corrêa (1944): Águas de Portugal minerais e de mesa: história e bibliografia. Lisboa: Direcção Geral de Minas e Serviços Geológicos, 6 vols.

Acciaiuoli, L. Menezes CorrêA (1947): Hidrologia portuguesa: 1943-1946. Lisboa: Direçcáo Geral de Minas e Serviços Geológicos.

Alarcấo, J. (2005): "Notas de arqueologia, epigrafia e toponímia-III", Revista Portuguesa de Arqueología, 8 (2), pp. 293-311.

39 Los casos de Lugo, Ourense, S. Pedro do Sul o Caldas de Vizela así como otros ejemplos del ámbito atlántico son analizados en González Soutelo, S. (2016): "De lo general a lo particular: el estudio de los balnearios de época romana en la fachada Atlántica de la Península Ibérica". En Actas I Simposium Aquae (Chaves, 2014). Chaves, en prensa.

40 Sobre esta apreciación $c f$. las consideraciones apuntadas en González Soutelo $(2012,2013)$ y en González Soutelo y Matilla Séiquer, op. cit. n. 38.
Andreu, J. (2010): "Indigenismo y romanización en Lusitania: Sobre el culto a las divinidades salutíferas acuáticas". En Gorges, J. G. y Nogales, T. (eds.): Naissance de la Lusitanie Romaine (Ier av.-Ier ap. J.C.). Actas VII Mesa Internacional sobre Lusitania Romana (Toulouse, 2007). Toulouse-Mérida, pp. 185-209.

Audin, P. (1985): "Les eaux chez les Arvernes et les Bituriges". En Pelletier, A. (dir.): La médicine en Gaule. Villes d'eaux, sanctuaires des eaux. Revue Archéologique du Centre de la France, 21-22. Paris: Piccard, pp. 12-144.

Bassani, M.; Bressan, M. y Ghedini, F. (eds.) (2013): Aquae salutiferae. Il termalismo tra antico e contemporaneo, Atti del convegno internazionale (Montegrotto Terme, 2012). Antenor Quaderni, 29. Pádova.

Bonnard, L. (1908): Gaule Thermale. Sources et stations thermales et minérales de la Gaule à l'époque gallo-romaine. Paris: Plon-Nourrit.

Capela, F. F. Gomes Simôes (2014): Contributos para o conhecimento da Pré-história Recente e da Proto-história da Serra de Monchique. Monchique: Arandis Edit.

Carneiro, S. Fiadeiro (2013): "As termas medicinais romanas de Chaves", Arqueologia em Portugal, 150 anos. Lisboa: Associação dos arqueólogos portugueses, pp. 793-802.

Carvalho, A. Da Silva (1939): Memórias das Caldas de Monchique. Lisboa: Comissão Administrativa das Caldas de Monchique.

Carvalho, A. Herculano de (1964): "Composição quimica dum tubo de chumbo da época romana (Caldas de Monchique)", Revista Portuguesa de Quimica. Facultade de Ciências, vi, pp. 35-37.

Chevallier, R. (ed.) (1992): Les eaux thermales et les cultes des eaux: en Gaule et dans les provinces voisines. Actes Colloque (Aix-Les-Bains, 1990). Paris: Centre de Recherches A. Piganiol.

Costa, J. De Sousa (1957, 2. a ed. [1944]): Alguns elementos para a elaboração do programa de edificação do novo balneário da estância termal das Caldas de Monchique. Monchique: Com. Administrativa das Caldas de Monchique.

Cruz, J. (ed.) (1992): Termas e águas engarrafadas em Portugal. Lisboa: Direcção-Geral de Geologia e Minas.

Cunliffe, B. (2000): Roman Bath discovered. Bath: Tempus Publishing.

Díez de Velasco, F. (1998): La sacralización del agua termal en la Península Ibérica y el norte de África en el

Zephyrus, LXXVIII, julio-diciembre 2016, 111-129 
mundo antiguo. Ilu: Revista de Ciencias de las Religiones, Monografías, 1. Madrid: Serv. Public. UCM.

EnCarnaçấo, J. (1984): Inscriçôes romanas do Conventus Pacensis: subsídios para o estudo da romanização. Coimbra: Instituto de Arqueologia da Fac. de Letras.

Fabiấ, C. (1999): "O Algarve romano". En Marques, M. G. (coord.): O Algarve. Da antiguidade aos nossos días (elementos para a sua história). Lisboa: Ediçôes Colibri.

Ferreira, O. da Veiga (1952): "Notícia sobre dois lagares antigos", Revista do Sindicato Nacional dos Engenheiros Auxiliares, Agentes Técnicos de Engenharia e Condutores, 75-76, pp. 52-57.

Ferreira, O. da Veiga (1963): “Acerca das ruínas do balineum lusitano-romano das Caldas de Monchique”, Revista Engenho, 18 (Jan-Março), pp. 13-17.

Fita, F. (1913): "Nuevas lápidas romanas de Santisteban del Puerto, Berlanga (Badajoz), Ávila y Retortillo (Salamanca)", Boletín de la Real Academia de la Historia, 62, pp. 529-545.

Formosinho, J. (1948): "Vestígios dos romanos nas Caldas de Monchique". En I Congresso Luso-Espanhol de hidrología. Lisboa: Ministerio da Economia, pp. 207-214.

Formosinho, J.; Ferreira, O. da Veiga y Viana, A. (1953): Estudos arqueológicos nas Caldas de Monchique. Porto: Porto Imprensa Portuguesa.

Frade, H. (1993): "As termas medicinais da época romana em Portugal”. En Actas II Congresso de História Antiga (Coimbra, 1990). Coimbra: Univ. Coimbra, pp. 873-916.

Frade, H. (1997): "Outros casos de establecimentos termais romanos em Portugal". En PeréX, M. ${ }^{a}$ J. (ed.): Termalismo antiguo. Actas I Congreso peninsular (Arnedillo, 1996). Madrid: Casa de Velázquez-Uned, pp. 303-306.

Franco, M. Lyster (1942): Diário de Notícias, n. ${ }^{\circ}$ 27599.

Franco, M. Lyster (1945): As termas romanas de Monchique. Monchique.

Gascon, J. A. Guerreiro (1993, 2. a ed. [1955]): Subsidios para a monografia de Monchique. Faro: Portimão MCRG Gascon.

González Soutelo, S. (2011): El valor del agua en el mundo antiguo: sistemas hidráulicos y aguas mineromedicinales en el contexto de la Galicia romana. A Coruńa: Fundación Barrié-csic.

GonzÁlez Soutelo, S. (2012): "Los balnearios romanos en Hispania. Puesta al día de los principales enclaves de aguas mineromedicinales en España”, Anales de Arqueología Cordobesa, 23-24, pp. 175-200.

GonzÁlez Soutelo, S. (2013): “¿De qué hablamos cuando hablamos de balnearios romanos? La arquitectura romana en los edificios de baños con aguas mineromedicinales en Hispania”, Cuadernos de Prehistoria y Arqueología Univ. Autónoma de Madrid, 39, pp. 123-150.

Guérin-Beauvois, M. y Martin, J.-M. (eds.) (2007): Bains curatifs et bains hygiéniques en Italie de l'Antiquité au Moyen Âge. Actes Colloque Rome, 2004. MEFRA, 383. Roma.

KöElHer, J. (2007): “Termalismo antico e tardoantico a Civitavecchia”. En Guérin-Beauvois, M. y MarTIN, J.-M. (eds.): Bains curatifs et bains hygiéniques en Italie de l'Antiquité au Moyen Âge. MEFrA, 383. Roma, pp. 115-126.

Mollière, H. (1893): Archéologie médicale. Mémoire sur le mode de captage et l'aménagement des sources thermales de la Gaule romaine, par le Dr. Humbert Mollière... Lyon: Côte edit.

Morán, E. y Parreira, R. (2009): “La exhibición del poder en el Megalitismo del suroeste peninsular: tres casos de estudio en el extremo sur de Portugal", Cuadernos de Prehistoria y Arqueología de la Universidad de Granada, 19, pp. 139-162.

Oró Fernández, E. (1996): "El balneario romano: Aspectos médicos, funcionales y religiosos", Antigüedad y Cristianismo: Monografías históricas sobre la Antigüedad Tardia, 13, pp. 23-152.

Pelletier, J. (ed.) (1985): La Médecine en Gaule: villes d'eaux, sanctuaires des eaux. Paris: Picard.

Perex Agorreta, M. ${ }^{2}$ J. (ed.) (1997): Termalismo antiguo. Actas I Congreso peninsular (Arnedillo, octubre 1996). Madrid: Casa de Velázquez-uned.

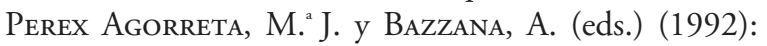
Termalismo antiguo. Espacio, tiempo y forma. Serie II, Historia antigua, 5. Madrid: UNED.

Rodrigues, S. (2004): As vias romanas do Algarve. Centro de Estudos do Patrimonio. Faro: Univ. Algarve.

Santos, M. L. y Estácio da Veiga, A. (1972): Arqueologia romana do Algarve. Dissertaçáo para Licenciatura em Ciências Históricas. Lisboa: Faculdade de Letras de Lisboa, vol. II.

Scheid, J.; Nicoud, M.; Bousseuil, D. y Coste, J. (eds.) (2015): Le thermalisme. Approches historiques et archéologiques d'un phénomène culturel et médical. Paris: CNRS. 
TAVARES, F. (1810): Instruçôes e cautelas prácticas sobre a natureza, differentes especies, virtudes em geral, e uso legitimo das aguas mineräes, principalmente de Caldas... Coimbra: Real Imprensa da Universidade.

Viana, A.; Ferreira, O. da Veiga y Formosinho, J. (1950): Estudos arqueológicos nas Caldas de Monchique. Investigaçôes de 1948 e 1949. Lisboa.

Viana, A.; Ferreira, O. da Veiga y Formosinho, J. (1955): Estudos arqueológicos nas Caldas de Monchique: relance das exploraçôes nas necrópoles da Idade do Bronze do ano de 1937 ao de 1949. Lisboa.
Viana, A.; Formosinho, J. y Ferreira, O. da Veiga (1943): O conjunto visigótico de Alcaria (Caldas de Monchique). Lisboa.

Viana, A.; Formosinho, J. y Ferreira, O. da Veiga (1948): Restos de caminhos romanos nas Caldas de Monchique. Lisboa: Natura.

Vv. AA. (1991): Luxovium: retour aux sources (Catalogue de l'exposition, Luxeuil-les-Bains, 1991). Besançon: CRDA. 